\title{
Maternity Insurance Fund Depletion and Universal Two-Child Policy in Qinghai Province in China
}

\author{
Henry Asante Antwi ${ }^{1 *}$, Tamires Lizandra Andrade Paixao ${ }^{2}$, Maxwell Opuni Antwi ${ }^{1}$ \\ 'School of Management, Jiangsu University, 301 Xuefu Road, Zhenjiang, P.R. China \\ ${ }^{2}$ Future Academy of Science and Technology, 3768 Hunan Highway, Shanghai, P.R China
}

\begin{abstract}
Article Info

Volume 8, Issue 4

Page Number : 465-478

Publication Issue

July-August-2021

\section{Article History}

Accepted : 20 July 2021

Published : 30 July 2021

Since the dawn of humanity, women have acquitted themselves creditably with this responsibility of childbirth even at the peril of their lives. Overtime, the politics, process and social mores that surround pregnancy and birth have evolved along with the growth and maturity of the medical profession, and the art and craft of motherhood. However, the introduction of the universal twochild policy in China without corresponding change in the income and expenditure mix of the maternity insurance schemes in Qinghai province threatens the sustainability of maternal health initiatives for minority ethnic groups in Western China. The analytical model used in this study hybridizes a system dynamics and actuarial model to express the maternity insurance expenditure and income function. The study noted that at the current contribution rate of $0.5 \%$, the maternity insurance fund in Qinghai province will be depleted by the end of 2020 and this can influence catastrophic maternal health crisis in the poorer region. The analysis also shows that if the contribution rate can be raised to $0.75 \%$, the depletion rate of the maternity insurance can be prolonged. We proposed an increase in the current rate of contribution of the maternity insurance fund in Qinghai province; improve investment income for the maternity insurance fund and other reliable sources of sustainable funding.

Keywords : Replenishing, maternity, insurance, women, health, China
\end{abstract}

\section{INTRODUCTION}

\section{BACKGROUND OF RESEARCH}

The experience of child bearing is both unique and universal and the biological composition of human beings has placed the task of giving birth solely in the bosom of women (Wellhoner et al., 2011). Since the dawn of humanity, women have acquitted themselves creditably with this responsibility even at the peril of their lives. Overtime, the politics, process and social mores that surround pregnancy and birth have evolved along with the growth and maturity of the medical profession, and the art and craft of motherhood (M. Huang et al., 2019). Also evolving is 
the politics and advocacy for the protection and greater vigilance to prevent women from losing their lives while bringing new life.

The Millennium fathers recognised this inalienable role of women by soliciting for unprecedented and extraordinary global commitment to maternal health in crafting the Millennium Development Goals (MDGs). Significantly, among the eight millennium development goals, the issue of maternal mortality reduction has proven to be one of the most difficult issues to deal with globally(Q. Wu et al., 2019). With the exception of China, many countries are far behind targets set to meet these goals on a national level (Yiwen Huang et al., 2019). The reasons adduced for the slow attainment of the MDG five varies.

For example the complexity involved in providing universal antenatal and delivery care (Li et al., 2019), the low economic status of most women across the globe (Wang, Zhou, Liang, \& Liu, 2020), marginalisation of women (P. Zhang, Wu, \& Xun, 2019) and the high concentration of women in rural areas who often lack high quality, accessible delivery care when needed are frontline reasons for the persistence and prevalence of maternal mortality across the globe (Wu, Huang, \& Shen, 2019). Also in (Chong et al., 2019), they contend that the low status of women in many parts of the world increases the chance of risky pregnancy, pregnancy at very young ages or at high parity, inadequate nutrition before and during pregnancy and poor or non-existent antenatal care delivery.

Three decades ago, the above listed factors were predominant in China but a new nation with rejuvenated maternal health priorities emerged at the turn of the millennium. Since the 1990s, China has made considerable progress in reducing maternal mortality to unprecedented levels through collaborative network of public-private partnership initiatives to protect women across the country(Ali, Cordero, Khan, \& Folz, 2019). (Gong, Chen, Gao, Su,
\& Chang, 2019) disclose that maternal health issues in China came to global attention in 1995 following the promulgation of the maternal and child health law. Inherent in this law was a national blueprint to prioritise resource allocation to improve the quality of maternal health services (Margaret et al., 2019). However, in the minority dominated provinces in Western China, the law was widely described as a law on eugenics (Whipps et al., 2019).

Since then several other laws, decrees, regulations, and measures have been promulgated in China to address imbalances in maternal health rights. Notable among these laws, regulations, decrees and measures are the Law on the Protection of Rights and Interests of Women (McKinn, Linh, Foster, \& McCaffery, 2019), the Law on Maternal and Infant Health, the Law on Population and Family Planning (Yuan Huang et al., 2019), the Regulation on the Placement of Surplus Staff and Workers of State-owned Enterprise (Z.-1. Zhao et al., 2019), the Notice on Several Matters concerning Maternity Benefits of Female Employees and the Special Regulation on Labour Protection of Female Employees.

In 1998, China took another giant step to protect maternal and child health by introducing and the Trial Measures on Maternity Insurance for Enterprise Staff and Workers (Huang et al., 2020). Following its success, the maternity insurance scheme was expanded in 2000 to all the provinces and autonomous regions in China to be administered at the local level. In so doing, authorities of province and autonomous regions were authorised to enact context and cultural specific regulations on maternity insurance that addresses perceived deficits in national maternal health policies to win the trust of women especially those from minority ethnic groups and poorer western territories and rural areas in the East (Yu \& Zhang, 2020). 
The success of these layers of social policy interventions to safeguard the health of women in China has resulted in the unprecedented decline of maternal mortality rate to 19.6 per 100,000 in 2017 from 19.9 per 100,000 the previous year. This remarkable nationwide decline in MMR at an average of $5.7 \%$ is three times higher than the average rate of decline of MMR in developing countries (Yu \& Zhang, 2020). In China's specific maternal health interventions have also focused on the institutionalisation of child birth that ensures that all deliveries occur in hospitals or quasi healthcare institutions in each part of the country. Moreover a new vigour has been injected into the antenatal and prenatal care system by the maternal health insurance system operated at the provincial level (Xiao et al., 2020). Through these interventions pregnant women are guaranteed a safer route to fulfilling their social responsibility of raising its young ones. To sustain this agenda, China uses media campaigns, improved healthcare infrastructure, staff training, referral networks and strict oversight responsibility at lower level hospitals(X. Zhao \& Davey, 2019). In some provinces, pregnant women are offered subsidies to attend hospitals while mandatory hospital deliveries have been successfully implemented in some major towns (Yao, Wu, Zhao, Luo, \& Zhang, 2019). To this end, community midwife programmes have been significantly discouraged in many provinces and resources are now concentrated on hospital deliveries.

Despite China's track record, poor rural areas, particularly in western China, continue to have lower rates of hospital deliveries and higher MMRs. While maternal mortality has declined in general terms across provinces, it remained significantly higher in the western region 2017 than in other areas (46.1 per 100,000 live births), compared with 29.1 for the central region and 17.8 for the East (Luo et al., 2019). As most of China's ethnic minorities live in the poorer western regions, the continuance of this syndrome keeps fuelling perception of inequitable distribution of the socio-economic worth for the collective good of all citizens.

However, the case of maternity insurance fund depletion is the most challenging issues currently facing the poor western regions with its potential catastrophic effect on maternal health(Gong et al., 2019). Five years into the implementation of the universal two-child policy in Chinese provinces, the maternity insurance scheme which was set up to reduce the economic burden of pregnant women before, during and after pregnancy, is facing serious depletion as a results of poor accumulation and investment of maternal health funds. It is also predicted that the universal two-child policy has increased the rate of utilisation of the maternity insurance fund leading to unprecedented deficit accumulation that threatens the lifespan of these funds. If this is not curtailed, the implication for maternal health in already deprived minority occupied regions may be disastrous.

Qinghai province is one of the western provinces in China with a large minority population that is at risk of an imminent depletion of the maternity insurance fund (Xue et al., 2019). A landlocked province located in the north-western part of China, Qinghai is the third largest province by land size in China but also the third smallest in terms of population and among the poorest in the whole of China (Hu et al., 2019). Qinghai Province sits on the Tibetan Plateau and borders other very poor provinces in China such as Gansu, Tibet Autonomous Region, Uyghur-Xinjiang Autonomous Region and the earthquake prone areas of the Sichuan Province.

The negative effect of collapsed maternal health insurance scheme insurance will be several in Qinghai since Qinghai houses several of China's less endowed, minority ethnic groups and a large number of poor majority ethnic group members. Altogether, there are over 37 recognized minority ethnic groups 
among Qinghai's 5.2 million residents. The distribution of the various ethnic groups in the province are the Han (54.5\%), Tu (Monguor) (4\%), Hui (16\%, Tibetan (20.7\%) and the Mongol, and Salar. Han Chinese are mostly found in Xining, Haidong, Delingha and Golmud, while the Hui are live mostly Xining, Haidong, Minhe County, Hualong County and Datong County (M. Huang et al., 2019). On the other hand, the Tu people occuy the Huzhu County and the Salars in Xunhua County. Finally, the Tibetans and Mongols are sparsely distributed across the rural western part of the province. Of the Muslim ethnic groups in China, Qinghai has communities of Hui, Salar, Dongxiang, and Bao'an. Qinghai is not an autonomous region in China for two reasons. Firstly the Han ethnic groups constitute the majority of the population and none of its ethnic minority groups have a clear dominance over the rest(Gu et al., 2019).

According Asante-Antwi (2019) to since 1970s several middle-aged women in Qinghai's municipalities were produced by population transfers to reflect a state policy to adjust the imbalanced gender ratios it had created in the 1950s. Today, Women constitute nearly half of the entire population and mostly work in the informal sector as farmers, farm hands and craft makers. In 2005, the MMR of Qinghai was 139 but declined to 104 in 2015, but it remained considerably higher, especially in rural areas, than the rate of 20 per 100,000 in Shanghai, Beijing, and Jiangsu, and Zhejiang provinces. A number of factors affect maternal health in Qinghai(Qi et al., 2019). For example, apart from Xining which is the provincial capital, other parts of Qinghai are underdeveloped and lack basic amenities. Qinghai ranks second lowest in China in terms of highway length which affect rapid movement to neighbouring regions to seek advanced medical care where necessary. As at 2017, $6.6 \%$ of villages around Qingnan, Yushu, Guoluo that sits nearly 3600 meters above sea level have no access to the telephone.
That withstanding, growing industrialisation has increased the formal sector participation of women in the economic activities in Qinghai's urban areas has increased rapidly since 2010. For example several women are now employed formally in the iron and steel production industries in Xining and the oil and gas production plants in the Qaidam Basin. As at 2017 more than $23.61 \%$ women were formally employed in numerous salt works across Qinghai's salt lakes (Q. Wu et al., 2019). Despite initial setbacks, Qinghai like many western provinces successfully implemented the maternity insurance scheme for formal sector urban women employees to boost maternal survivability (Ding et al., 2019).

The decision to establish the maternity insurance systems was to reduce the economic burden of expecting mothers by providing them with material assistance and alleviate their mental stress resulting from the opportunity costs during pregnancy. In Qinghai as it pertains in other provinces, the contribution rate by companies has been set as low as 0.05 of the basic or living wage (Chen et al., 2019). The low contribution rate is fast increasing the deficit levels of the maternity insurance funds. This is because the contribution rate was set with the onechild policy in mind and low enough to deter employers from avoiding the recruitment of female workers. With the introduction of the comprehensive two-child policy, the expenditure burden of the maternal insurance fund has accentuated leading to unprecedented rate of attrition of the maternity insurance funds (Ning, 2019).

In a province that faces shortage of health resources, poor communication and high concentration of women in the informal sector with little social support, an unsustainable maternity insurance for the few urban and formally engaged women will invariably deepen an already precarious maternal health situation in Qinghai (Gui \& Chen, 2020). To alleviate this challenge and respond to the current gap 
in literature, our study uses a novel systems dynamic model to establish the influence of the comprehensive two child policy and other factors on the maternity insurance depletion. Through sensitive analysis, we identify an appropriate range of contribution rates of maternal insurance fund to support a sustainable maternal health insurance scheme in Qinghai. We identify the implications of such a choice considering the precarious standard of living of the area. Future research direction is outlined before concluding on the research.

\section{MATERIALS AND METHODS}

\section{Data Source}

Data for the study was collected from four main databases. These were the Qinghai Statistical Year Book and the National Bureau of Statistics. Data was also collected from the Knoema Enterprise Data Solutions and the 2018 Social Insurance Rates in China by China Labour Watch. The last two sources provide publicly available information on national statistics such as mortality rates, birth-rates, GDP and social health insurance data across the provinces of China. Some of the data that was collected from these sources were the contribution rate of the maternity insurance, maternity insurance fund income, maternity insurance fund expenditure, payment rate of maternity insurance, average wage of insured people, the number of insured people, the average level of treatment, the number of people who enjoy treatment, the number of newly insured people, birth rate, death rate, total population of Qinghai Province etc. Other data was computed as secondary results by combining two or more primary data or through extrapolation from the primary data. The period of this study covered 2012 to 2017 due to the availability of data.

\section{Analytical Model}

This study used a hybrid model which incorporate a first order systems dynamic model and first order actuarial model to compute maternity insurance premium rate and its sensitivities. The actuarial model is first used to mathematically express the income and expenditure equation of the maternity insurance fund whereas the systems dynamic model is used to analyse the relationship between the variables. Consistent with prior studies (Long, Zhang, Xu, Tang, \& Hemminki, 2010)and (X. Zhang, Zhou, \& Antwi, 2019), income inflow into the maternity insurance fund $(M F I)_{t}$, depends on the payment rate $(M P R)_{t}$ and the payment base $(M P B)_{t}$. The payment base also depends on the average wage of insured person or social wage $(M A P)_{t}$ and the number of insured persons $(M I N)_{t}$,.Thus the actuarial equation of the maternity insurance fund income in Qinghai Province can be expressed mathematically as;

$$
\begin{aligned}
& M F I_{t}=(M P R)_{t} \times(M P B)_{t}=(M P R)_{t} \times \\
& {\left[(M A P)_{t} \times(M I N)_{t}\right] \quad \text { Equation } 1}
\end{aligned}
$$

On the other hand the maternity insurance fund expenses for year $\mathrm{t}(M F E)_{t}$ depend on the per capita (average) utilization cost $(M A T)_{t}$ and the number of beneficiaries in a year $(M E N)_{t}$. The number of beneficiaries in a year also depends on the number of insured persons $(M I N)_{t}$, the number of newly insured people in year $t\left(S N_{t}\right)$, the frequency of insurance fund utilization denoted by the rate of birth $\left(b r_{t}\right)$, the death rate of women $\left(d r_{t}\right)$, the probability of an insured person giving birth to twins (1/89) probability of an insured person giving birth to twins as proposed by (X. Zhang et al., 2019) and the effect of birth promotion policy such as the universal twochild policy which came into effect in 2015. We thus incorporated (natc) $t$ as the modeled increment to the number of beneficiaries of maternity insurance as a result of the two-child policy in year t. Our final actuarial model for the attrition rate of the maternity insurance fund is mathematically expressed as;

$$
\begin{gathered}
M F E_{t}=(M A T)_{t} \times(M E N)_{t}=(M A T)_{t} \times \\
\left\{\left[\left((M I N)_{t}+S N_{t}\right) \times b r_{t}\right]-\left[\left((M I N)_{t}+S N_{t}\right) \times d r_{t}\right]-\right. \\
\left.\left[0.011236\left((M I N)_{t}+S N_{t}\right) \times b r_{t}\right]+(\text { natc })_{t}\right\} \\
\text { Equation } 2
\end{gathered}
$$

Due to the universal two-child policy, women who hitherto had a single chance of giving birth now have 
more than one chance to give birth hence can utilise the maternity insurance fund more often than in the one-child policy era. This is without prejudice to the fact that not every woman would want to have two children or have a child at all. Further, it is also the case that the one-child policy did not affect most minority ethnic women in Qinghai,. However, a spillover is because Qinghai Province has a high concentration of majority ethnic group members. Secondly, the population covered by second-child alone in Qinghai Province is relatively small. In June 2015, only 273, 212 persons had applied for the second child only and 153,371 were granted the permission. The universal two-child policy is much wider as it targets a higher population group hence may have a bigger impact.

The nationwide implementation can increase the inflow of new born babies in the future and will largely increase maternity insurance utilization, the maternity insurance fund expenditure and which can speed up the depletion of the fund. Prior to the implementation of the universal two-child policy, the Qinghai Province recorded an average birth-rate over 13 years from 2000 to 2015. By 2017, the birth rate had exceeded $14.42 \%$. This significant leap is attributable to the spillover of the comprehensive two-child policy. This will require an upward adjustment in the contribution rate of maternity insurance to ensure its sustainability. Taking these into consideration, we mathematically compute the effect of the second child policy (natc) ${ }_{t}$ for Qinghai Province using the following actuarial model;

$$
(\text { natc })_{t}=(N C T)_{t} \times \frac{(M I N)_{t}}{(T P)_{t}}
$$

where (natc) $)_{t}$ represents new additions to insured population of the Qinghai Province in year $t$ resulting from the two-child, $(N C T)_{t}$ represents new additions to the population of Qinghai Province in year $t$ resulting from the two-child policy and $(T P)_{t}$ representing the total population of Qinghai Province in year t. According to the Statistical
Yearbook of Qinghai Province in 2017, the ratio of the number of people insured in the maternity insurance scheme in Qinghai Province to the total population remained around 0.18 . The calculation shows that the number of newly-born children in Qinghai's maternity insurance group is about 10,000 each year. Our final model for the accumulated balance of the maternity insurance fund $(M F B)_{t}$ is expressed mathematically as

$$
\begin{gathered}
\mathrm{S}\left(\mathrm{t}_{\mathrm{x}}\right)=\mathrm{S}\left(\mathrm{t}_{\mathrm{x}-1}\right)+\int_{\mathrm{t}_{\mathrm{x}-1}}^{\mathrm{t}_{\mathrm{x}}} \operatorname{rateS}\left(\mathrm{t}_{\mathrm{x}}\right) \mathrm{dt} \\
=\mathrm{S}\left(\mathrm{t}_{\mathrm{x}-1}\right)+\left[(M F I)_{\mathrm{t}_{\mathrm{x}}}-(M F E)_{\mathrm{t}_{\mathrm{x}}}\right] \times 1 \\
=\mathrm{S}\left(\mathrm{t}_{\mathrm{x}-1}\right)+\left[(M F I)_{\mathrm{t}_{\mathrm{x}}}-(M F E)_{\mathrm{t}_{\mathrm{x}}}\right] \\
(M F B)_{t_{x}}=\mathrm{S}\left(\mathrm{t}_{0}\right)+\left[\left(\int_{\mathrm{t}_{0}}^{\mathrm{t}_{1}} \operatorname{rateS}\left(\mathrm{t}_{1}\right) \mathrm{dt}\right)+\cdots\right. \\
\left.+\left(\int_{\mathrm{t}_{\mathrm{x}-1}}^{\mathrm{t}_{\mathrm{x}}} \operatorname{rateS}\left(\mathrm{t}_{\mathrm{x}}\right) \mathrm{dt}\right)\right] \\
=\mathrm{S}\left(\mathrm{t}_{0}\right)+\sum_{t=t_{1}}^{t_{x}}\left(\int_{\mathrm{t}_{\mathrm{x}-1}}^{\mathrm{t}_{\mathrm{x}}} \operatorname{rateS}\left(\mathrm{t}_{\mathrm{x}}\right) \mathrm{dt}\right) \\
+\sum_{t=t_{1}}^{t_{x}}\left\{\left[(M F I)_{\mathrm{t}_{1}}-(M F E)_{\mathrm{t}_{1}}\right]\right. \\
+\left[(M F I)_{\mathrm{t}_{2}}-(M F E)_{\mathrm{t}_{2}}\right]+\cdots \\
\left.+\left[(M F I)_{\mathrm{t}_{\mathrm{x}}}-(M F E)_{\mathrm{t}_{\mathrm{x}}}\right]\right\} \\
=\mathrm{S}\left(\mathrm{t}_{0}\right)+\sum_{t=t_{1}}^{t_{x}}\left\{\left[(M F I)_{\mathrm{t}}-(M F E)_{\mathrm{t}}\right]\right\}
\end{gathered}
$$

The maternity insurance t-year fund income $(M F I)_{t}$ and maternity insurance t-year fund expenditure $(M F E)_{t}$ generations can be obtained using the following formula;

$$
\begin{gathered}
(M F B)_{t_{x}}=\mathrm{S}\left(\mathrm{t}_{0}\right)+\sum_{t=t_{1}}^{t_{x}}\left\{\left[(M P R)_{t} \times(M A P)_{t} \times(M I N)_{t}\right]\right. \\
\left.-\left[(M A T)_{t} \times(M E N)_{t}\right]\right\}
\end{gathered}
$$


$=\mathrm{S}\left(\mathrm{t}_{0}\right)$
$+\sum_{t=t_{1}}^{t_{x}}\left\{-\left[\begin{array}{c}{\left[(M P R)_{t} \times(M A P)_{t} \times(M I N)_{t}\right]} \\ \left(\left((M I N)_{t}+S N_{t}\right) \times b r_{t}\right)- \\ \left(\left((M I N)_{t}+S N_{t}\right) \times d r_{t}\right)- \\ \left(0.011236\left((M I N)_{t}+S N_{t}\right) \times b r_{t}\right)\end{array}\right)\right]$

where $\mathrm{S}\left(\mathrm{t}_{\mathrm{x}}\right)=(M F B)_{t_{x}} \mathrm{~S}\left(\mathrm{t}_{0}\right)$ means the balance of maternity insurance fund at year $t_{0}$.

\section{System Dynamic Model}

Due to the complexity of the interactions of factors indicated in the actuarial model, a system dynamic model that incorporates three subsystems i.e. (economic subsystem, utilization subsystem and population subsystem) was designed to analyze the actual model. The utilization subsystem is sandwiched between the economic subsystem (top) and the population subsystem (down) intertwined by a seamless set and network of relationships and interrelations that justifies the application of a systems dynamic model for analysis.

Further, applying systems dynamic model may help answer a question posed by (W. Zhang, 2004) on whether western development strategies can narrow down China's regional disparity. Previous studies have ignored the influence of value-added income to the fund such as interest of the maternity insurance fund, penalty for late fees etc as they constitute a small amount of income inflow into the maternity insurance fund(X. Zhang et al., 2019). The variables and functional relationships of the maternity insurance system dynamics model for Qinghai Province is shown in table 1 . All the data were derived from the historical data whereas the Statistical Yearbook of Qinghai Province and from the survey. The final maternity insurance systems dynamic inflow is given as follows

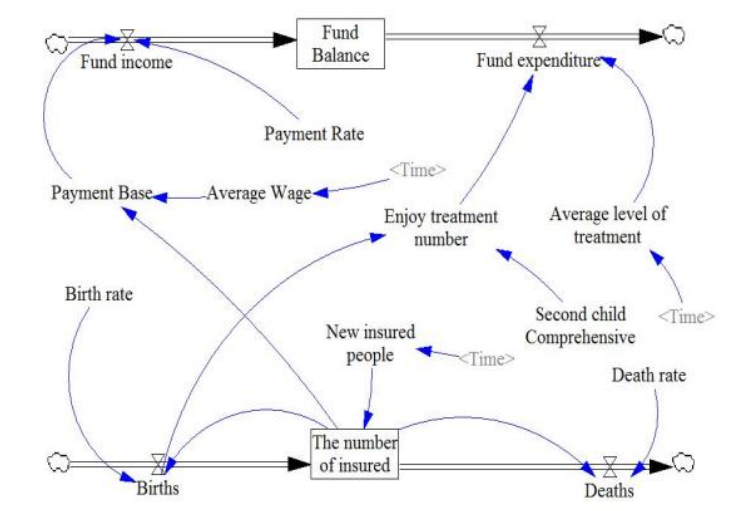

Figure 1 : Systems dynamic model for maternity insurance fund flow in China as adopted from (X. Zhang et al., 2019)

\section{RESULTS}

Test of Goodness of Fit

Table 1: Test of Consistency of Maternity Insurance Fund Income and Expenditure

\begin{tabular}{ccccccc}
\hline & $\begin{array}{c}\text { Actual Income } \\
\text { of the } \\
\text { Maternity } \\
\text { Insurance } \\
\text { Income (billion) }\end{array}$ & $\begin{array}{c}\text { Simulated Income } \\
\text { Value of Maternity } \\
\text { Insurance }\end{array}$ & $\begin{array}{c}\text { Relative } \\
\text { Error }\end{array}$ & $\begin{array}{c}\text { Actual Expenditure } \\
\text { of the Maternity } \\
\text { Insurance Fund } \\
\text { (billion) }\end{array}$ & $\begin{array}{c}\text { Expenditure Value of } \\
\text { the Maternity } \\
\text { Insurance Fund }\end{array}$ & $\begin{array}{c}\text { Relative } \\
\text { Error }\end{array}$ \\
\hline 2012 & 11.5 & 11.72 & -0.0031 & 6.57 & 8.42 & 0.001 \\
2013 & 15.2 & 14.92 & -0.0045 & 10.03 & 9.01 & -0.001 \\
2014 & 17.32 & 17.63 & 0.004 & 12.39 & 12.61 & -0.004 \\
2015 & 19.16 & 20.48 & 0.0028 & 16.20 & 14.72 & -0.03 \\
2016 & 18.15 & 19.69 & -0.0003 & 20.74 & 19.58 & 0.003 \\
\hline
\end{tabular}

Source : Qinghai Statistical Yearbook and the results of the System Dynamics Simulation 
As a test of goodness of fit, recent data from the statistical yearbook for the period 2012-2016 was used to simulate the system dynamic model to establish its goodness of fit i. e. the consistency of the simulated data and the actual data for the period. Table 2 shows that the relative results of the test variables (actual values of the maternity insurance fund income, expenditure and the number of enrolment) are within $10 \%$ and most of them were within $5 \%$ error. This confirms the robustness of the model (strong goodness of fit). Moreover its parameters variation represents the development trend of variables therefore scenario analysis can be conducted and conclusions therefrom.

Sensitivity Test

Two sets of sensitivity tests were run to measure how much change will occur in the model results based on percentage change in the number of utilization and the rate of premium payment set by government.

\section{Sensitivity Analysis of Number of Utilization as a result of Two-child Policy}

In scenario 1 , the current rate of premium contribution which is the $0.5 \%$ of the wages of employees or the national social wage is set as a control variable i.e. (remains constant) but the rate of utilization as a result of increase in population is varied between $50 \%$ and $150 \%$. From the previous calculations, an expected number of 10,000 new born babies will be added to the population of per Qinghai as a result of the universal two-child policy. Thus at $50 \%$ policy efficiency level, the number of utilization will increase by 5000 while a $150 \%$ policy efficiency level will mean 15000 additional new births and possible fund utilization will be generated. Figure 2 shows the sensitivity of the maternity insurance fund balance to changes in utilization efficiency levels as a result of the universal two-child policy. The information shows that as the number of new additions increases due to arrival of second children (with a constant rate of contribution to the maternity insurance funds), the rate of depletion increases correspondingly and this puts the sustainability of the maternity insurance fund at risk without a corresponding increase in the fund balance.

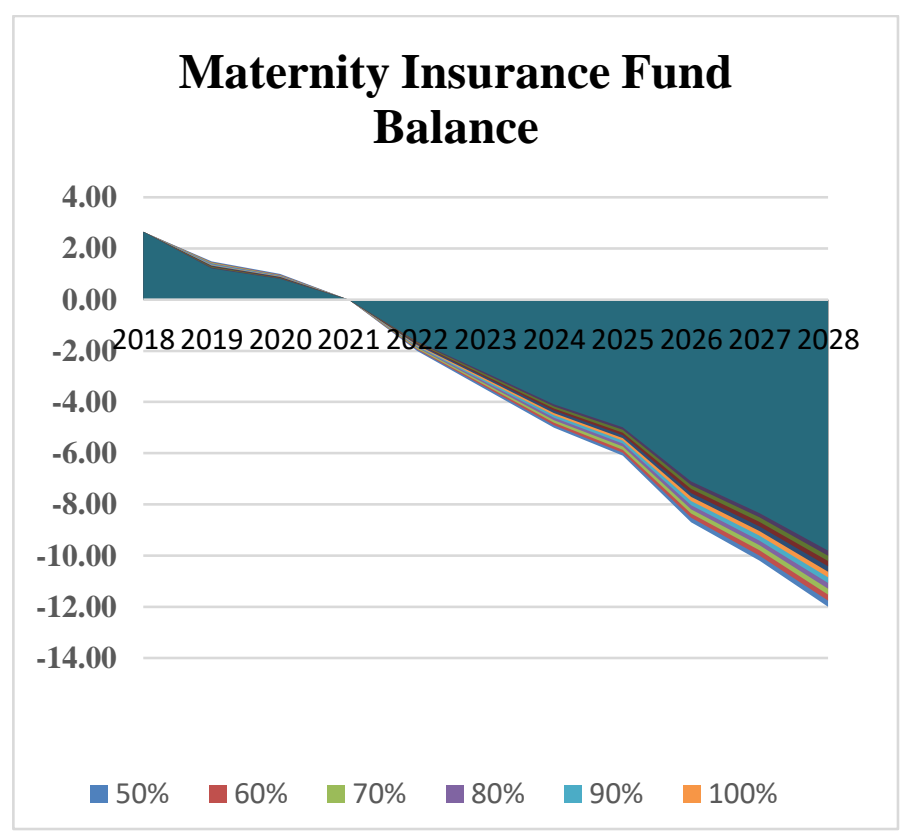

Figure 1 : Sensitivity test on the balance of maternity insurance after two-child policy in Qinghai province

\section{Sensitivity Analysis of Maternity Insurance Policy}

In second scenario, the number of additions to the utilization per-annum as a result of universal two child policy is held constant at $10000 \quad(100 \%$ efficiency rate) based on previous computation. The contribution rate of the maternity insurance is instead varied since it is the easiest way way by which the government can influence maternity insurance policies. In 2015, the Chinese government issues Policy Document 331 that indicates that any future change in the contribution rate of maternity insurance in China will be between $0.45 \%$ (worstcase scenario) and $1 \%$ (best-case scenario). This means that an unlikely increase of the contribution rate to $1 \%$ will lead to a $10 \%$ increment in fund balance. If the current contribution rate of $0.005 \%$ is adjusted over a range between $90 \%$ and $200 \%$, the trend in the time to deficit and time to depletion of the maternity insurance fund is shown in figure 3 


\section{Maternity Insurance Fund Balance}

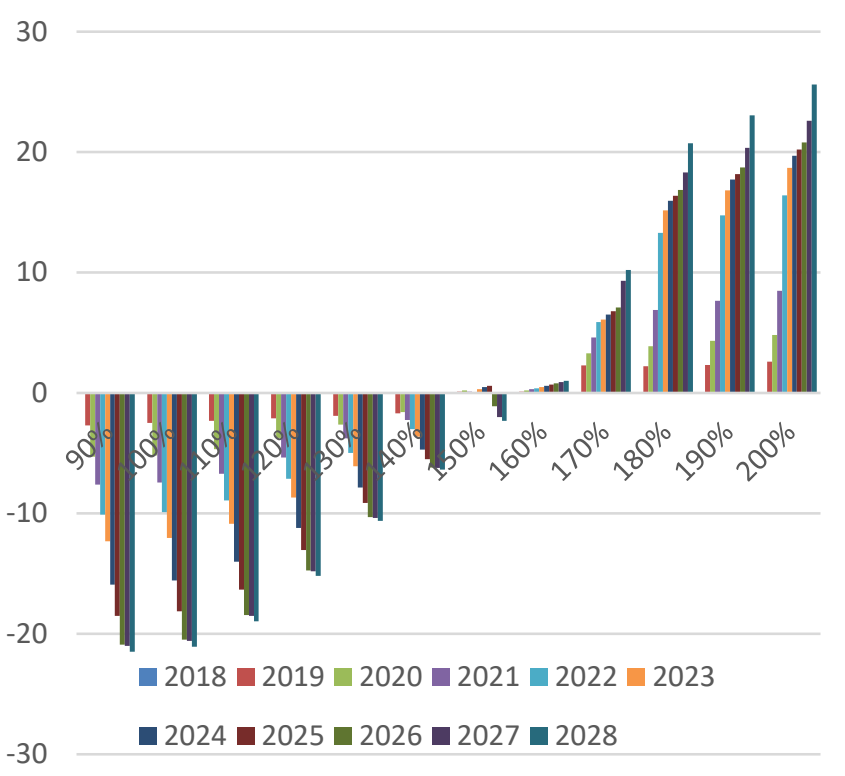

Figure 2 : Sensitivity test on the analysis of maternity insurance policy under different parameters and scenarios

The information in figure 3 shows the operational results for the sensitivity analysis under different parameters and scenarios to adjust the contribution rate. The trend shows that the rate of contribution set by the government has substantial influence on the future sustainability of the maternity insurance fund. If the current contribution rate $(0.5 \%)$ increases by less than $100 \%$, it will speed up the deficit of the maternity insurance fund.

On the other if the contribution rate changes by $150 \%$ (increasing the maternity insurance rate from $0.5 \%$ to $0.75 \%$ ), the maternity insurance fund balance will increase and this will extend the deficit accumulation period for the maternity insurance in Qinghai Province. This information affirms the fact that the universal two-child policy requires proper adjustment to contribution rate to maintain the sustainability of the maternity insurance fund in Qinghai Province.
Table 2 : Prediction of the deficit trend of the maternity insurance fund in Qinghai Province and the dynamic adjustment strategy under the effects of universal two-child policy

\begin{tabular}{cccccc}
\hline $\begin{array}{c}\text { Policy } \\
\text { efficiency }\end{array}$ & $\begin{array}{c}\text { Additio } \\
\text { nal } \\
\text { Births }\end{array}$ & $\begin{array}{c}\text { Rate } \\
\text { of } \\
\text { Payme } \\
\text { nt }\end{array}$ & $\begin{array}{c}\text { Curre } \\
\text { nt } \\
\text { deficit } \\
\text { time }\end{array}$ & $\begin{array}{c}\text { Depletion } \\
\text { Time }\end{array}$ & $\begin{array}{c}\text { Adjuste } \\
\text { d } \\
\text { Paymen } \\
\text { t Rate }\end{array}$ \\
\hline $50 \%$ & 5000 & $0.5 \%$ & 2019 & 2021 & $0.72 \%$ \\
$60 \%$ & 6000 & $0.5 \%$ & 2019 & 2021 & $0.73 \%$ \\
$70 \%$ & 7000 & $0.5 \%$ & 2019 & 2021 & $0.73 \%$ \\
$80 \%$ & 8000 & $0.5 \%$ & 2019 & 2021 & $0.73 \%$ \\
$90 \%$ & 9000 & $0.5 \%$ & 2019 & 2021 & $0.74 \%$ \\
$100 \%$ & 10000 & $0.5 \%$ & 2019 & 2021 & $0.74 \%$ \\
$110 \%$ & 11000 & $0.5 \%$ & 2019 & 2021 & $0.75 \%$ \\
$120 \%$ & 12000 & $0.5 \%$ & 2019 & 2021 & $0.75 \%$ \\
$130 \%$ & 13000 & $0.5 \%$ & 2019 & 2021 & $0.76 \%$ \\
$140 \%$ & 14000 & $0.5 \%$ & 2019 & 2021 & $0.76 \%$ \\
$150 \%$ & 15000 & $0.5 \%$ & 2018 & 2020 & $0.77 \%$ \\
\hline
\end{tabular}

\section{Source: Simulated Results}

The final table 2, presents the output of the simulated results the range of adjustments that must be effected to sustain the maternity insurance fund in Qinghai Province active. At different levels of additional new births triggered by the universal two-child policy, if the current contribution rate of $0.5 \%$ remains unchanged, the fund balance will plunge into deficit in 2019 and the entire maternity insurance fund will be completed depleted by 2021. If on the other hand the government increase the contribution rate from $0.5 \%$ to $0.74 \%$, then even if at $100 \%$ effectiveness rate of the new policy which will drive new births by 10000, the maternity insurance fund will generate a surplus balance until 2028. The information in the table gives a general picture suggestion that anytime the new births as a results of the universal two-child policy (natc) $t$ rises or decline by about 2000 , the contribution rate must be adjusted corresponding by 0.0001 adjustment (increase/decrease) of need to be done in the contribution rate needs of $0.1 \%$ must be effected to maintain a surplus balance on the maternity insurance fund between 2018 and 2028. 


\section{DISCUSSION AND CONCLUSION}

This paper was intended to achieve two main objectives. Firstly it sought to establish the extent to which the universal two-child policy in China has had an effect on maternity insurance fund in Qinghai Province. Secondly, the study sought to simulate the rate of attrition of the maternity insurance fund and the change in maternity insurance contribution rate that can reduce the rate of depletion of the maternity insurance fund income in Qinghai province. Qinghai province was selected for two main reasons. Firstly it is among the poorest regions in China hence any negative change in health related social interventions such as the maternity insurance fund can lead to catastrophic health outcomes. Similarly, a lot of China's minority ethnic groups especially the $\mathrm{Tu}$ (Monguor), Hui, Tibetan, Mongol, Salar, Dongxiang, and Bao'an live in the Qinghai province (Gu et al., 2019).

With constant accusation of neglect of minority health rights against the Chinese government, ensuring a stable health insurance scheme for wouldbe mothers is a conditional imperative to safeguarding minority health security. Beside these things China leadership in Millennium Development Goal 5 must be consolidated as the country affirms the global trust in its health priorities amidst invading human right accusations against minority ethnic groups(Ali et al., 2019). In response to the first research objective as to whether the comprehensive two-child policy has had any effect on the maternity insurance fund, the available evidence shows a strong influence on the rate of deficit accumulation by the new policy.

The analysis shows that even though the number of births has not escalated as predicted with the introduction of the comprehensive two child policy, there has been a significant increase in the number of new births which has increased the pressure on the maternity insurance scheme than in the past. The effect of that the expenditure of the maternity insurance scheme has increased without a corresponding increase in the inflow into the fund. This is largely because the maternity insurance fund contribution rate has remained unchanged for a considerable period of time and there is no other major source of income into the maternity insurance fund in Qinghai province. The analysis further indicates that by 2019, the maternity insurance fund in Qinghai province will accumulate high deficits and the entire maternity insurance fund in the province will be completely depleted by the end of 2021. These findings are consistent with available studies in other parts of China that suggest that the maternity insurance scheme is currently under excessive stress and requires unprecedented effort to prolong their lifespans. This study reveals that first and foremost the administrators in the Qinghai province must increase the rate of contribution of the maternity insurance paid by the employers. The Chinese government has indicated that any future increase/decrease of the rate will be between $0.4 \%$ at worst and $1 \%$ at best. From the simulation it is observed that if the contribution rate is pegged at $0.75 \%$ it will prolong the lifespan of the maternity insurance scheme. This implies that while an increase in the contribution rate is a good option but can only serve as a temporary measure(Hu et al., 2019). This is even more important because a very high contribution rate will deter companies from employing female employees (Gu et al., 2019).

\section{REFERENCES}

[1]. Ali, Moazzam, Cordero, Joanna Paula, Khan, Faria, \& Folz, Rachel. (2019). 'Leaving no one behind': a scoping review on the provision of sexual and reproductive health care to nomadic populations. BMC Women's Health, 19(1), 161.

[2]. Chen, Yuji, Lee, Yuan-Chin Amy, Li, Shuang, Li, Qian, Chen, Chien-Jen, Hsu, Wan-Lun, ... . Shen, Hongbing. (2019). Body mass index and 
the risk of head and neck cancer in the Chinese population. Cancer epidemiology, 60, 208-215.

[3]. Chong, Ka Chun, Rui, Yan, Liu, Yan, Zhou, Tianyuan, Jia, Katherine, Wang, Maggie Haitian, . . . He, Hanqing. (2019). Early Waning of Maternal Measles Antibodies in Infants in Zhejiang Province, China: A Comparison of Two Cross-Sectional Serosurveys. International journal of environmental research and public health, 16(23), 4680.

[4]. Ding, Wenguang, He, Li, Zewudie, Dinka, Zhang, Huilin, Zafar, Tanjia Binte, \& Liu, Xinde. (2019). Gender and renewable energy study in Tibetan pastoral areas of China. Renewable energy, 133, 901-913.

[5]. Gong, Guangwen, Chen, Yingchun, Gao, Hongxia, Su, Dai, \& Chang, Jingjing. (2019). Has the Efficiency of China's Healthcare System Improved after Healthcare Reform? A Network Data Envelopment Analysis and Tobit Regression Approach. International Journal of Environmental Research and Public Health, 16(23), 4847.

[6]. Gu, Yuxuan, Zhang, Hao, Ali, Shahmir H, Huang, Minzhuo, Wei, Jingming, Gu, Shuyan, . . . Dong, Hengjin. (2019). Social Determinants of Health-Related Quality of Life among Residents in Zhejiang and Qinghai, China. International journal of environmental research and public health, 16(8), 1314.

[7]. Gui, Shixun, \& Chen, Jieling. (2020). Average life expectancy of the Chinese population in 1949-2019: trends, contributors and prospects. China Population and Development Studies, 3(2), 142-153.

[8]. Hu, Xiaoqian, Zhang, Hao, Sun, Xueshan, Gu, Yuxuan, Zhen, Xuemei, Gu, Shuyan, ... Dong, Hengin. (2019). Older adults' choices of first-contact care and related factors in Zhejiang and Qinghai Province, China. Geriatrics \& gerontology international, 19(9), 938-944.
[9]. Huang, Minzhuo, Zhang, Hao, Gu, Yuxuan, Wei, Jingming, Gu, Shuyan, Zhen, Xuemei, ... . Dong, Hengjin. (2019). Outpatient healthseeking behavior of residents in Zhejiang and Qinghai Province, China. BMC public health, 19(1), 967.

[10]. Huang, Yiwen, Wang, Lijuan, Huo, Junsheng, Wu, Qiong, Wang, Wei, Chang, Suying, \& Zhang, Yanfeng. (2019). Prevalence and causes of anaemia in children aged 6-23 months in rural Qinghai, China: findings from a crosssectional study. BMJ open, 9(9), e031021.

[11]. Huang, Yuan, Martinez-Alvarez, Melisa, Shallcross, David, Pi, Li, Tian, Fan, Pan, Jay, \& Ronsmans, Carine. (2019). Barriers to accessing maternal healthcare among ethnic minority women in Western China: a qualitative evidence synthesis. Health policy and planning, 34(5), 384-400.

[12]. Huang, Yue, Wang, Xi, Yang, Yuning, Qu, Xueqi, Wang, Anqi, Huang, Xiaona, \& Zhou, Hong. (2020). The role of education in maternal depressive symptoms among different ethnic groups: A cross-sectional study in rural western China. Journal of affective disorders, 262, 359365.

[13]. Li, Hong-tian, Xue, Ming, Hellerstein, Susan, Cai, Yue, Gao, Yanqiu, Zhang, Yali, ... L Liu, Jian-meng. (2019). Association of China's universal two child policy with changes in births and birth related health factors: national, descriptive comparative study. bmj, 366, 14680.

[14]. Long, Qian, Zhang, Tuohong, Xu, Ling, Tang, Shenglan, \& Hemminki, Elina. (2010). Utilisation of maternal health care in western rural China under a new rural health insurance system (New Co-operative Medical System). Tropical Medicine \& International Health, 15(10), 1210-1217.

[15]. Luo, Min, Zhao, Ziling, He, Linkun, Su, Bingzhong, Liu, Weixin, \& Zhang, Gang. (2019). Ethnic disparity in pneumonia-specific 
mortality among children under 5 years of age in Sichuan Province of Western China from 2010 to 2017. BMC Public Health, 19(1), 1-8.

[16]. Margaret, Maimbolwa Connie, Patricia, Mukwato Katowa, Mutinta, Muleya, Concepta, Kwaleyela, Victoria, Kalusopa Mwiinga, Musenge, Emmanuel, ... Stray-Pedersen, Babil. (2019). Women's Experience with SocioEconomic Factors Associated with Perinatal Morbidity and Mortality in Lusaka and Mumbwa Districts of Zambia. Health, 11(06), 733.

[17]. McKinn, Shannon, Linh, Duong Thuy, Foster, Kirsty, \& McCaffery, Kirsten. (2019). A qualitative analysis of factors that influence Vietnamese ethnic minority women to seek maternal health care. BMC pregnancy and childbirth, 19(1), 243.

[18]. Ning, Gu. (2019). Education of Women Since the Founding of the People's Republic of China: Achievements, Problems and Countermeasures Women, Family and the Chinese Socialist State, 1950-2010 (pp. 287-308): Brill.

[19]. Qi, Yinyan, Zhu, Chunyun, Chen, Jinfu, Liu, Guiying, Yang, Zhanwu, \& Chen, Wusheng. (2019). Comparative analysis of the quality and health-promoting compounds of two-shaped fruits of wild Lycium ruthenicum Murr. from the Qinghai-Tibet Plateau. Acta Physiologiae Plantarum, 41(6), 101.

[20]. Wang, Jiazhou, Zhou, Yueyue, Liang, Yiming, \& Liu, Zhengkui. (2020). A Large Sample Survey of Tibetan People on the Qinghai-Tibet Plateau: Current Situation of Depression and Risk Factors. International Journal of Environmental Research and Public Health, 17(1), 289.

[21]. Wellhoner, Mary, Lee, Anne CC, Deutsch, Karen, Wiebenga, Mariette, Freytsis, Maria, Drogha, Sonam, . . . Khandro, Dawa. (2011). Maternal and child health in yushu, qinghai province, china. International Journal for Equity in Health, 10(1), 42.

[22]. Whipps, Mackenzie DM, Miller, Elizabeth B, Bogen, Debra L, Mendelsohn, Alan L, Morris, Pamela A, Shaw, Daniel, \& Gross, Rachel S. (2019). Breastfeeding Behaviors and Maternal Interaction Quality in a Low-Income, Ethnic Minority Population. Journal of Developmental \& Behavioral Pediatrics.

[23]. Wu, Qiong, Huang, Yiwen, van Velthoven, Michelle Helena, Wang, Wei, Chang, Suying, \& Zhang, Yanfeng. (2019). The effectiveness of using a WeChat account to improve exclusive breastfeeding in Huzhu County Qinghai Province, China: protocol for a randomized control trial. BMC public health, 19(1), 1-10.

[24]. Wu, Xiaohua, Huang, Zhengzheng, \& Shen, Shaowu. (2019). Comprehensive Evaluation of Medical Service Ability of TCM Hospitals in 30 Provinces, Autonomous Regions and Municipalities of China in 2017 Based on Entropy Weight TOPSIS Method and RSR Method. Paper presented at the Proceedings of the 2019 The World Symposium on Software Engineering.

[25]. Xiao, Yuanyuan, He, Liping, Chang, Wei, Zhang, Shinan, Wang, Rui, Chen, Xiaowen, ... Risch, Harvey A. (2020). Self-harm behaviors, suicidal ideation and associated factors among rural left-behind children in west China. Annals of Epidemiology.

[26]. Xue, Zhiqiang, Yang, Zhenbo, Sun, Hui, Ren, Jinghuan, Sun, Mengzi, Li, Jiagen, . . . Dou, Jing. (2019). Epidemiological analysis of respiratory and intestinal infectious diseases in three counties of Sichuan: the baseline survey of Disaster Mitigation Demonstration Area in western China. PeerJ, 7, e7341.

[27]. Yao, Minghong, Wu, Gonghua, Zhao, Ziling, Luo, Min, \& Zhang, Juying. (2019). Unintentional injury mortality among children under age five in urban and rural areas in the 
Sichuan province of west China, 2009-2017. Cite this article as :

Scientific reports, 9(1), 1-8.

[28]. Yu, Xuexin, \& Zhang, Wei. (2020). All-cause mortality rate in China: do residents in economically developed regions have better health? International Journal for Equity in Health, 19(1), 12.

Henry Asante Antwi, Tamires Lizandra Andrade Paixao, Maxwell Opuni Antwi, " Maternity Insurance Fund Depletion and Universal Two-Child Policy in Qinghai Province in China ", International Journal of Scientific Research in Science and

[29]. Zhang, Ping, Wu, Jingguo, \& Xun, Nan. (2019). Role of Maternal Nutrition in the Health Outcomes of Mothers and Their Children: A Retrospective Analysis. Medical science monitor: international medical journal of Technology(IJSRST), Print ISSN : 2395-6011, Online ISSN : 2395-602X, Volume 8, Issue 4, pp.465-478, July-August-2021. Available doi : https://doi.org/10.32628/IJSRST218468 experimental and clinical research, 25, 4430.

[30]. Zhang, Wei. (2004). Can the strategy of western development narrow down China's regional disparity? Asian Economic Papers, 3(3), 1-23.

[31]. Zhang, Xiaotian, Zhou, Lvlin, \& Antwi, Henry Asante. (2019). The impact of China's latest population policy changes on maternity insurance-a case study in Jiangsu Province. The International journal of health planning and management, 34(1), e617-e633.

[32]. Zhao, Xiang, \& Davey, Gareth. (2019). Areca nut use among a Chinese ethnic minority, and its health implications. Substance use \& misuse, 1-6.

[33]. Zhao, Zi-ling, Yao, Ming-hong, Zhang, Gang, Wu, Gong-hua, Zhang, Li, Zhang, Ju-ying, \& Ma, Xiao. (2019). All-cause child mortality in minority and non-minority areas in Sichuan Province in Western China, 2008-2017. Scientific reports, 9(1), 1-7. 